\title{
Numerical studies for effect of geometrical parameters on water jet pump performance via entropy generation analysis
}

\author{
M.P. Helios ${ }^{1,3}$ and W. Asvapoositkul ${ }^{2}$ \\ ${ }^{1}$ The Joint Graduate School of Energy and Environment, King Mongkut's University of Technology Thonburi, Bangkok, Thailand \\ 2 Department of Mechanical Engineering, Faculty of Engineering, King Mongkut's University of Technology Thonburi, Bangkok, Thailand \\ Phone: (662) 470-9123; Fax: (662) 470-9111 \\ ${ }^{3}$ Center of Excellence on Energy Technology and Environment (CEE), PERDO, Ministry of Higher Education, Science, Research and Innovation, \\ Bangkok, Thailand
}

\begin{abstract}
This paper presented an implementation of entropy generation analysis in the main flow field of a water jet pump via the CFD method. This study aimed to identify the inefficient location of energy conversion and to analyse entropy generation sources in each region of the water jet pump. The 2D-axisymmetric model and realisable $k-\varepsilon$ (RKE) turbulence model at steadystate conditions were performed to validate jet pump performance and to assess the entropy generation. Likewise, the effects of the projection ratio $\left(L_{x}^{*}\right)$ and throat-aspect ratio $\left(L_{t}^{*}\right)$ as independent parameters were investigated. As a result, the throat is the most inefficient part due to the high total entropy generation rate, following by diffuser part. Also, the entropy generation rate was assessed dominant than viscous dissipation due to the turbulent dissipation, which was caused by a turbulent shear stress layer of mixing the streams. In conclusion, the projection ratio influenced the growth of the shear stress layer as well as the entropy generation. Further, the throat-aspect ratio affected the distribution of entropy generation in the throat section. An appropriate combination of both parameters has an impact on the jet pump performance improvements reducing the entropy generation rate in the future.
\end{abstract}

ARTICLE HISTORY

Received: $20^{\text {th }}$ May 2020

Revised: $28^{\text {th }}$ Jan 2021

Accepted: $25^{\text {th }}$ Feb 2021

\section{KEYWORDS}

Water jet pump;

2D axisymmetric model; entropy generation analysis; projection ratio;

throat-aspect ratio.

\section{INTRODUCTION}

A water jet pump is a kind of subsonic ejector type, of which liquid is used as both motive (driving) and secondary (driven) flow. It utilises the force of a high-pressure fluid stream to boost the pressure. It may also affect the flow of a low-pressure fluid stream. It is widely used and found in many industries, i.e., chemical, petrochemical, energy conversion, and food industry. The main features of the jet pump are simplicity, reliability, durability, relatively low cost, and absence of moving parts. However, it has relatively low efficiency caused by irreversibilities, e.g., friction, jet flow, fluid stream mixing, recirculation, and pressure recovery[1,2]. Irreversibilities are not able to be eliminated, but it is possible to be controlled by appropriate combination operating conditions and geometry design [3]. The system consists of the inlet for primary (motive fluid), inlet for secondary fluid, suction chamber, converging section (mixing chamber), throat, diverging section (diffuser), and discharge pipe (see Figure1).

According to the geometry of the jet pump, it has the following dimensionless parameters: (a) the nozzle-throat area ratio or ratio of nozzle area to the throat area $\left(A_{o n-t}^{*}=\left(\frac{d_{o n}}{d_{t}}\right)^{2}\right)$, (b) the throat-aspect ratio or ratio of throat length to throat diameter $\left(L_{t}^{*}=\frac{l_{t}}{d_{t}}\right)$, (c) converging-diverging section angle ratio or ratio of convergent section angle to divergent section angle $\left(\theta_{c d}^{*}=\frac{\alpha}{\beta}\right)$, (d) projection ratio or ratio of the distance between the nozzle tip and throat entry to throat diameter $\left(L_{x}^{*}=\frac{x}{d_{t}}\right)$, and (e) suction chamber area ratio or ratio of suction chamber area to the outlet nozzle area $\left(A_{s-o n}^{*}=\left(\frac{d_{s}^{2}}{d_{t}^{2} A_{o n-t}^{*}}\right)-1\right)[4,5]$. On the performance evaluation of a well-designed water jet pump, the pump geometric conditions including projection ratio $\left(L_{x}^{*}\right)$ and throat-aspect ratio $\left(L_{t}^{*}\right)$ can be adjusted easily to define its optimum operating parameters and pump component efficiencies. Based on the literature reviews, it has been found that these design parameters and their effects on the performance of the pump were not sufficiently studied using experiment and numerical simulation. Under different operating conditions and geometry, the suggested range of projection ratio and throat-aspect ratio for water jet pumps based on the experiment is $0.5-1$ and $5-8$, respectively [6-9].

In recent years, numerical studies via CFD simulation on jet pump performance are preferred for many reasons. The results can be represented in visual form to analyse the flow structure and reveal the transport mechanisms in the flows of fluid. Various studies have dealt with comparisons and review dealing with the design parameter of the water jet pump [9-14]. 
As a fundamental approach to energy loss analysis, the second law of thermodynamics promotes the benefits of entropy generation. The usefulness of entropy generation analysis associated with the process or component can be used to identify and to minimise the thermodynamic losses (irreversibilities). In CFD, entropy is calculated from the final phase of the simulation. It is widely used, especially in turbomachinery [15-18], heat exchanger [19], and two-phase flow ejector [20-21]. Gong et al. [15] study the effects of guide vane opening in the hydro-turbine performance. The study revealed that the guide opening at $16.65^{\circ}$ has the optimum performance and the minimum entropy generation. Hou, et al. [16] implemented entropy generation modelling to learn phenomena relating to entropy generation in the LNG submerged pump. The study claimed that separation flow, shock phenomenon and vortex were considered as a source of entropy generation. Sierra- Pallares et al. [20] studied entropy generation in three different mixing chambers by the 2D axisymmetric approach. They claimed that the turbulent dissipation contributes to more than $75 \%$ of the entropy generation depending on mixing chamber geometry. In addition, Helios \& Asvapoositkul [21] investigated entropy generation rate distribution in the two-phase flow ejector zones by concerning the effects of increasing velocity and temperature of motive fluid. The results revealed that the throat section contributed to the highest energy dissipation. However, the entropy generation proportion in each region depends on the operating conditions.

Currently, there is no study concerning the entropy generation application for determining energy loss in terms of entropy generation in the water jet pump. The performance of the water jet pump depends on the high-pressure stream of fluid about the pump through its geometry. Along with the geometry shape, the key dimensionless parameters which can be adjusted during the operation are projection ratio $\left(L_{x}^{*}\right)$ and throat-aspect ratio $\left(L_{t}^{*}\right)$. These two parameters and their effects on the performance of the pump are, therefore investigated in this numerical study. The numerical results are validated with experimental data. Numerical determination of the optimal values for these parameters make it possible to provide for a feasible design of the optimal jet pump geometry in the given available high-pressure fluid stream. The optimal geometry of the jet pump makes it possible to ensure the required pump performance (delivery, head, and efficiency). The 1st law of thermodynamics is used to determine overall system efficiency while the 2 nd law of thermodynamic is used to identify loss sources and their mechanism. This data would not only add to the geometry of water jet pump knowledge for design purposes but permit further study of cavitation phenomena.

\section{CFD MODELLING STRATEGY}

The water jet pump employed in this study was a single-stage water jet pump. The prototype of the water jet pump is presented in Figure 1. It was designed with a throat diameter $\left(d_{t}\right)$ of $12.7 \mathrm{~mm}$ in order to operate with driving pressure of motive flow at $400 \mathrm{kPa}$ absolute. The dimensionless variables are $A_{o n-t}^{*}=0.303 ; L_{t}^{*}=7 ; \theta_{c d}^{*}=5.7 ; L_{x}^{*}=1$; and $A_{s-o n}^{*}=$ 47.61 .

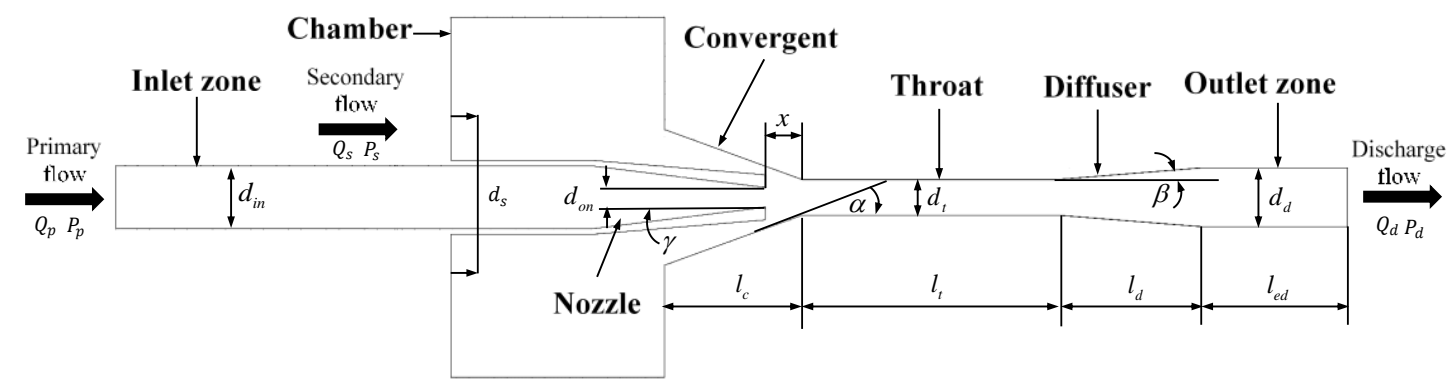

Figure 1. Schematic parameters of water jet pump

\section{Governing Equations and Boundary Conditions}

The CFD simulation was employed by using ANSYS Fluent. The two-dimensional axisymmetric approach was used to determine water jet pump performance and energy loss in terms of entropy generation rate. The governing equations form, i.e., continuity, axial momentum, radial momentum, and energy of the steady RANS for incompressible of the 2D axisymmetric model can be expressed as follow [22]:

$$
\begin{gathered}
\frac{\partial}{\partial x}(\rho u)+\frac{1}{r} \frac{\partial}{\partial r}(\rho r v)=0 \\
\frac{1}{r} \frac{\partial}{\partial x}(\rho r u u)+\frac{1}{r} \frac{\partial}{\partial r}(\rho r u v)=\frac{\partial P}{\partial x}+\frac{1}{r} \frac{\partial}{\partial x}\left\{r \mu\left[2 \frac{\partial u}{\partial x}-\frac{2}{3}\left(\frac{\partial u}{\partial x}+\frac{\partial v}{\partial r}+\frac{v}{r}\right)\right]\right\} \\
+\frac{1}{r} \frac{\partial}{\partial r}\left[r \mu\left(\frac{\partial u}{\partial r}+\frac{\partial v}{\partial x}\right)\right]
\end{gathered}
$$




$$
\begin{gathered}
\frac{1}{r} \frac{\partial}{\partial x}(\rho r u v)+\frac{1}{r} \frac{\partial}{\partial r}(\rho r v v)=\frac{\partial P}{\partial x}+\frac{1}{r} \frac{\partial}{\partial x}\left[r \mu\left(2 \frac{\partial v}{\partial x}-\frac{\partial u}{\partial r}\right)\right] \\
+\frac{1}{r} \frac{\partial}{\partial r}\left\{r \mu\left[2 \frac{\partial v}{\partial x}-\frac{2}{3}\left(\frac{\partial u}{\partial x}+\frac{\partial v}{\partial r}+\frac{v}{r}\right)\right]\right\} \\
-2 \mu \frac{v}{r^{2}}+\frac{2 \mu}{3 r}\left(\frac{\partial u}{\partial x}+\frac{\partial v}{\partial r}+\frac{v}{r}\right) \\
\frac{\partial}{\partial x}\left(u\left(\rho C_{p} T+P\right)\right)+\frac{1}{r} \frac{\partial}{\partial r}\left(v\left(\rho C_{p} T+P\right)\right)=\frac{\partial}{\partial x}\left(\lambda_{\text {eff }} \frac{\partial T}{\partial x}\right)+\frac{1}{r} \frac{\partial}{\partial r}\left(\lambda_{e f f} r \frac{\partial T}{\partial x}\right)+\mu \Phi
\end{gathered}
$$

where $C_{p}, \lambda_{\text {eff }}, \mu$ and $\Phi$ represent the specific heat at constant pressure, effective thermal conductivity, viscosity and viscous dissipation, respectively. The relation between total viscosity and effective viscosity can be written as follows.

$$
\begin{gathered}
\left|\frac{\alpha+1.3929}{\alpha_{0}+1.3929}\right|^{0.6321} \times\left|\frac{\alpha+2.3929}{\alpha_{0}+2.3929}\right|^{0.3679}=\frac{\mu}{\mu_{e f f}} \\
\alpha_{0}=\frac{\lambda}{\mu C_{p}}
\end{gathered}
$$

where $\mu_{e f f}, \alpha$, and $\alpha_{0}$ stand for the effective viscosity, inversed-effective Prandtl number and base Prandtl number, respectively. Hence, the effective viscosity can be determined by Eq. (7).

$$
\mu_{e f f}=\rho C_{\mu} \frac{k}{\varepsilon}
$$

where $k, \varepsilon$ and $C_{\mu}$ stand for turbulence kinetic energy, turbulence dissipation rate and turbulence model constant. Then, viscous dissipation term for the axisymmetric model can be written as:

$$
\Phi=2\left[\left(\frac{\partial u}{\partial x}\right)^{2}+\left(\frac{\partial v}{\partial r}\right)^{2}+\left(\frac{v}{r}\right)^{2}\right]+\left(\frac{\partial v}{\partial x}+\frac{\partial u}{\partial r}\right)^{2}
$$

Furthermore, geometry has two inlets and an outlet. Both inlet boundaries were set up as total pressure inlet, while the outlet boundary was set as static pressure, as shown in Figure 2. The flow inside the pump was assumed to be the steady-state and incompressible flow. No-slip wall condition was set at the wall. The standard wall function was selected to solve phenomena near the wall. The heat transfer between water and surroundings did not exist, and the effect of gravitational acceleration was neglected because of the insignificant effect of it's to the short distance of fluid flow. The quadrilateral grid generation was applied in each region. Considering the high turbulent Reynold number, the inflated grid was generated to satisfy the boundary layer structure. In this case, the $\mathrm{y}^{+}$value was treated at the viscous sub-layer and log-law region. The splitting zone techniques were used to maintain the grid quality aspects, i.e., minimum orthogonal quality and maximum skewness of each zone at an acceptable range and also to maintain the stability of simulation. The mesh quality and $\mathrm{y}^{+}$value were listed in Table 1 . Both mesh quality and independency were checked for obtaining accurate solutions for the water jet pump.

Table 1. Grid quality and $\mathrm{y}^{+}$value

\begin{tabular}{cccccccc}
\hline \multirow{2}{*}{ Grid Criteria } & \multicolumn{7}{c}{ Region } \\
\cline { 2 - 8 } & $\begin{array}{c}\text { Inlet } \\
\text { zone }\end{array}$ & Nozzle & Chamber & Convergent & Throat & Diffuser & $\begin{array}{c}\text { Outlet } \\
\text { zone }\end{array}$ \\
\hline Orthogonal quality & 0.63 & 0.56 & 0.88 & 0.79 & 0.88 & 0.84 & 0.56 \\
Skewness & 0.57 & 0.58 & 0.43 & 0.53 & 0.43 & 0.44 & 0.58 \\
${\text { Average } y^{+}}^{+}$ & 0.62 & 2.00 & 3.50 & 23.84 & 2.45 & 2.19 & 1.53 \\
${\text { Maximum } y^{+}}^{1.49}$ & 5.71 & 6.93 & 76.57 & 3.32 & 3.42 & 1.61 \\
\hline
\end{tabular}




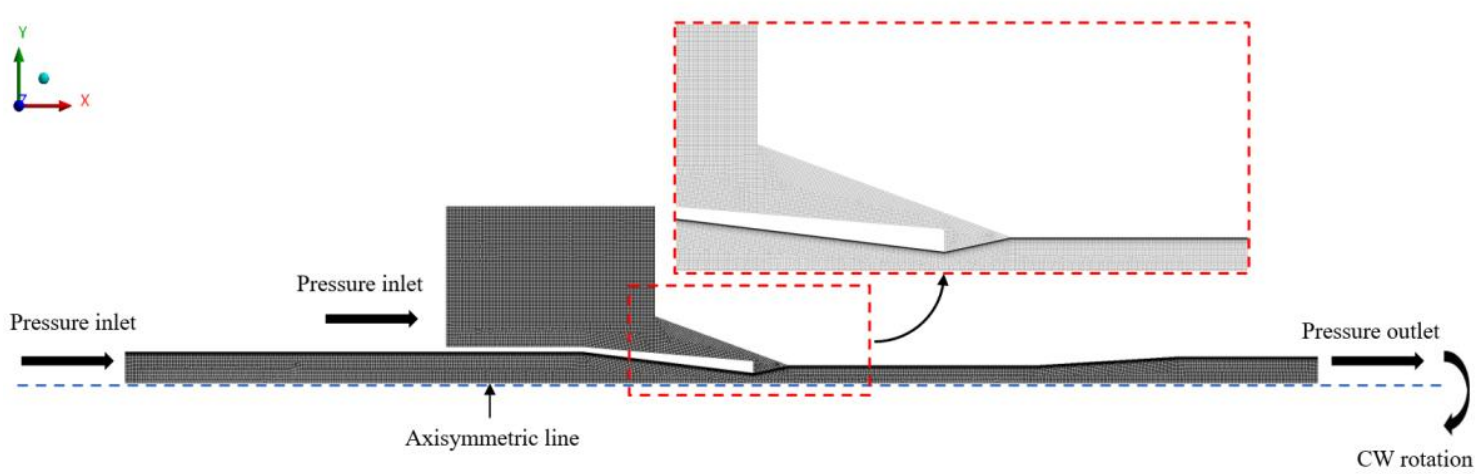

Figure 2. 2D axisymmetric grid and boundary conditions

Turbulence is a property of the flow rather than of the fluid; hence, a proper turbulence model should be incorporated into the fluid flow characteristics to predict the results accurately. The authors performed six turbulence models, i.e., standard $k-\varepsilon$ (SKE), realisable $k-\varepsilon$ (RKE), RNG $k-\varepsilon$ (RNG-KE), standard $k-\omega$ (SKO), SST $k-\omega$ (SST-KO), and Transitional SST (TSST) for water jet pump applications. Comparisons with experimental data show that all the turbulence models give reasonably good agreement. Based on this analysis, the RKE model was the most accurate turbulence model following by SKO, TSST, SST, RNGKE, and SKE. This turbulence model was also valid to be used in the annular water jet pump with different boundary conditions [23, 24].

\section{Performance Evaluation}

The jet pump performance was evaluated based on CFD results and compare to experimental data. The performance of the jet pump is associated with the volume flow rate and pressure changes. Two non-dimensionless ratios, i.e., the volumetric ratio $\left(Q^{*}\right)$ and pressure ratio $\left(P^{*}\right)$ are introduced as performance parameters. Both parameters can be written as follows [7]:

$$
\begin{gathered}
Q^{*}=\frac{\text { Volume flowrate of secondary fluid }}{\text { Volume flow rate of primary fluid }}=\frac{\mathrm{Q}_{\mathrm{s}}}{\mathrm{Q}_{\mathrm{p}}} \\
P^{*}=\frac{\text { Secondary fluid pressure rise }}{\text { Primary fluid pressure drop }}=\frac{P_{d}-P_{s}}{P_{p}-P_{d}}
\end{gathered}
$$

Where $Q$ and $P$ represent volume flow rate $(\mathrm{L} / \mathrm{min})$ and absolute pressure $(\mathrm{Pa})$, respectively, while subscript $p, s$, and $d$ stand for primary, secondary, and discharge, respectively (see Figure 1). Hence, the performance of the jet pump ( $\eta$ ) the equation can be written as follows:

$$
\eta=\frac{\text { Energy gained in secondary fluid }}{\text { Energy supplied by primary fluid }}=\frac{\mathrm{Q}_{\mathrm{s}}}{\mathrm{Q}_{\mathrm{p}}} \times \frac{P_{d}-P_{S}}{P_{p}-P_{d}}
$$

\section{Entropy Generation Modelling}

The irreversibilities process causes energy dissipation in the energy conversion mechanism in the main flow field. It has a strong relationship with apparent entropy generation in the system [25]. The entropy generation rate can be expressed as the sum of contribution due to viscous and thermal effects. In this study, both temperature and velocity fields are known. Hence, the volumetric or local entropy generation rate $\left(\dot{s}_{g e n}^{\prime \prime \prime}\right)$ at each point can be calculated as follows:

$$
\dot{s}_{g e n}^{\prime \prime \prime}=\dot{s}_{g e n, D}^{\prime \prime \prime}+\dot{s}_{g e n, H}^{\prime \prime \prime}
$$

The two terms in the right-hand side stand for total entropy generation by viscous effects $\left(\dot{s}_{g e n, D}\right)$, and thermal effects $\left(\dot{s}_{g e n, H}\right)$, respectively. Both entropy terms are simplified as:

$$
\begin{gathered}
\dot{s}_{g e n, D}^{\prime \prime \prime}=\frac{\mu_{e f f}}{T}\left(2\left[\left(\frac{\partial u}{\partial x}\right)^{2}+\left(\frac{\partial v}{\partial r}\right)^{2}+\left(\frac{v}{r}\right)^{2}\right]\right)+\left(\frac{\partial v}{\partial x}+\frac{\partial u}{\partial r}\right)^{2} \\
\dot{s}_{g e n, H}^{\prime \prime \prime}=\frac{\lambda}{T^{2}}\left[\left(\frac{\partial T}{\partial x}\right)^{2}+\left(\frac{\partial T}{\partial r}\right)^{2}\right]
\end{gathered}
$$


For the case of isothermal, entropy generation is only due to viscous effects. For turbulent flows, time-averaged entropy generation by viscous effects is divided into two parts, i.e., viscous dissipation $\left(\dot{s}_{g e n, \bar{D}}^{\prime \prime \prime}\right)$ and turbulent dissipation $\left(\dot{s}_{g e n, D^{\prime}}^{\prime \prime \prime}\right)$. The entropy generation by viscous effect or dissipation can be expressed as

$$
\dot{s}_{g e n, D}=\dot{s}_{g e n, \bar{D}}^{\prime \prime \prime}+\dot{s}_{g e n, D^{\prime}}^{\prime \prime \prime}
$$

By involving the time-averaging process, entropy generation due to viscous dissipation terms can be expressed as:

$$
\begin{gathered}
\dot{s}_{g e n, \bar{D}}^{\prime \prime \prime}=\frac{\mu_{\text {eff }}}{\bar{T}}\left[2\left[\left(\frac{\partial \bar{u}}{\partial x}\right)^{2}+\left(\frac{\partial \bar{v}}{\partial r}\right)^{2}+\left(\frac{\bar{v}}{r}\right)^{2}\right]+\left(\frac{\partial \bar{v}}{\partial x}+\frac{\partial \bar{u}}{\partial r}\right)^{2}\right] \\
\dot{s}_{g e n, D^{\prime}}^{\prime \prime \prime}=\frac{\mu_{e f f}}{\bar{T}}\left[2\left[\overline{\left(\frac{\partial u^{\prime}}{\partial x}\right)^{2}}+\overline{\left(\frac{\partial v^{\prime}}{\partial r}\right)^{2}}+\overline{\left(\frac{v^{\prime}}{r}\right)^{2}}\right]+\overline{\left(\frac{\partial v^{\prime}}{\partial x}+\frac{\partial u^{\prime}}{\partial r}\right)^{2}}\right]
\end{gathered}
$$

However, local entropy generation rate by turbulent dissipation $\left(\dot{s}_{g e n, D^{\prime}}^{\prime \prime \prime}\right)$ is not possible to calculate directly, since the fluctuating velocity component is not accounted on the RANS approach [26]. Since all RANS turbulence models provide information about the turbulent dissipation rate $\varepsilon$ and the mean temperature $(\bar{T})$ in the flow field. Further, Kock and Herwig [25] introduced the local entropy generation rate by turbulent dissipation as written in Eq. (18).

$$
\dot{s}_{g e n, D^{\prime}}^{\prime \prime \prime}=\frac{\rho \varepsilon}{\bar{T}}
$$

Thus, the total entropy generation rate over the volume $\left(\dot{s}_{g e n}\right)$ can be quantified as follows:

$$
\dot{s}_{g e n=} \int_{V} \dot{s}_{g e n}^{\prime \prime \prime} \partial \theta \cdot \partial r . \partial x
$$

Where $\mathrm{V}$ is the volume and $r$ is radial distance.

\section{RESULTS AND DISCUSSION}

\section{Numerical Validation}

In this study, the water jet pump geometry is similar to Figure 1 with $L_{t}^{*}=7$, and $L_{x}^{*}=1$. With a suitable adjustment, i.e., the pump geometry, to fit the experimental data, we could compare calculated values with experimental data. In these calculations, the turbulence effects were modelled by the realisable $k$ - $\varepsilon$ turbulence model (RKE). Steady calculations were performed in the case for high-pressure water was flow through the primary inlet. In contrast, atmosphere water was flow through the secondary inlet, and the static pressure was specified at the outlet duct. Solutions were obtained for a range of flow rates so that water jet pump performance was generated and compared with the available data. The values of the volumetric ratio $\left(Q^{*}\right)$, pressure ratio $\left(P^{*}\right)$ and pump efficiency $(\eta)$ based on equations (9)-(11) were calculated and compared with that of experimental data, as shown in Figure 3 [27]. The CFD results are under predicted with respect to the experimental data. The margin error of $Q^{*}$ and $P^{*}$ was within $\pm 5 \%$, and that of $\eta$ was within $\pm 10 \%$.

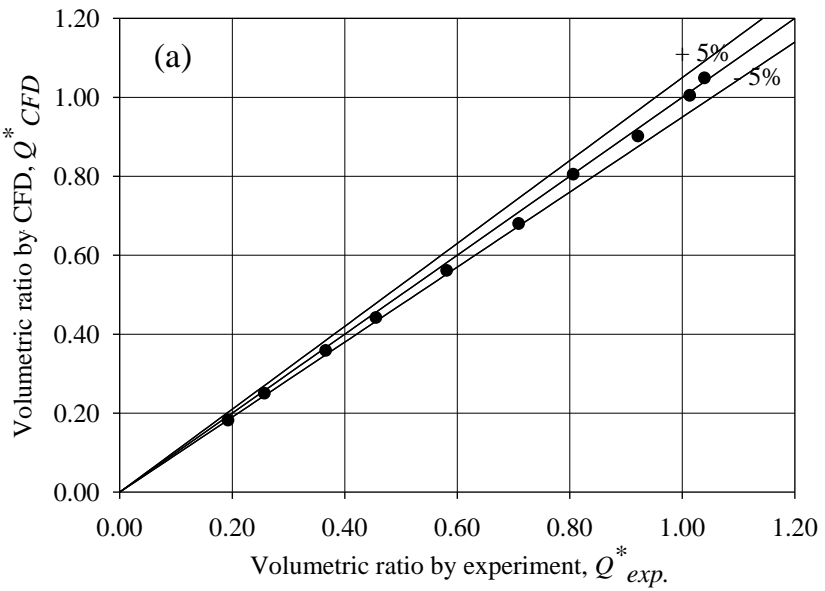

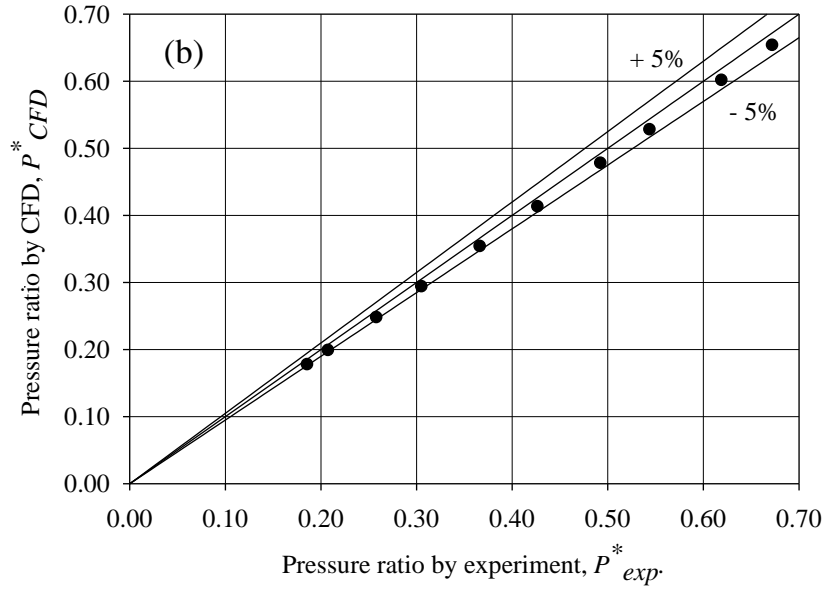




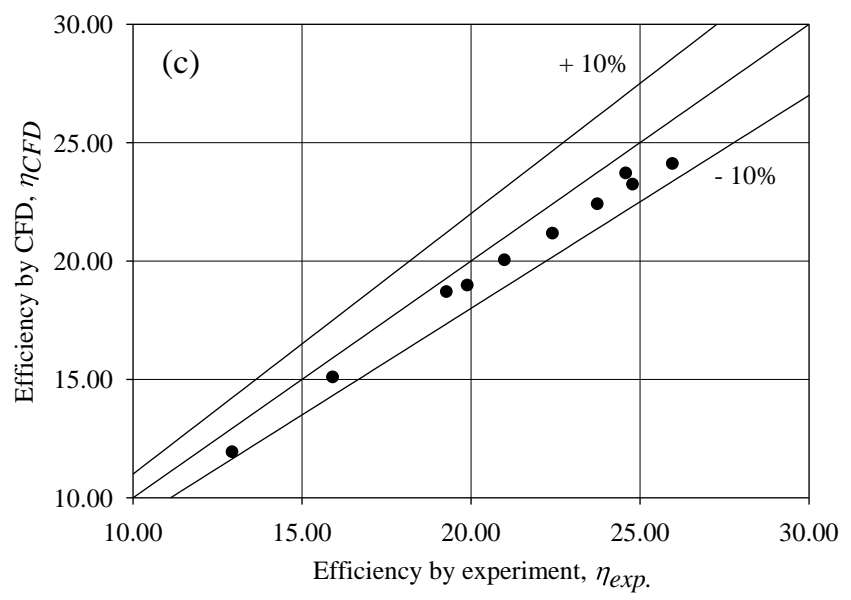

Figure 3. Numerical results validation by RKE turbulence model (a) volumetric ratio, (b) pressure ratio and (c) efficiency

The main aim of a designer of a water jet pump is to minimise loss. We can expect that when the loss is minimum, water jet pump efficiency is maximum. It is possible to use entropy generation to predict energy loss in different designs at different locations such as the mixing chamber or discharge pipe. Figure 4 depicts where the minimum entropy generation rate is proportional to optimum efficiency.

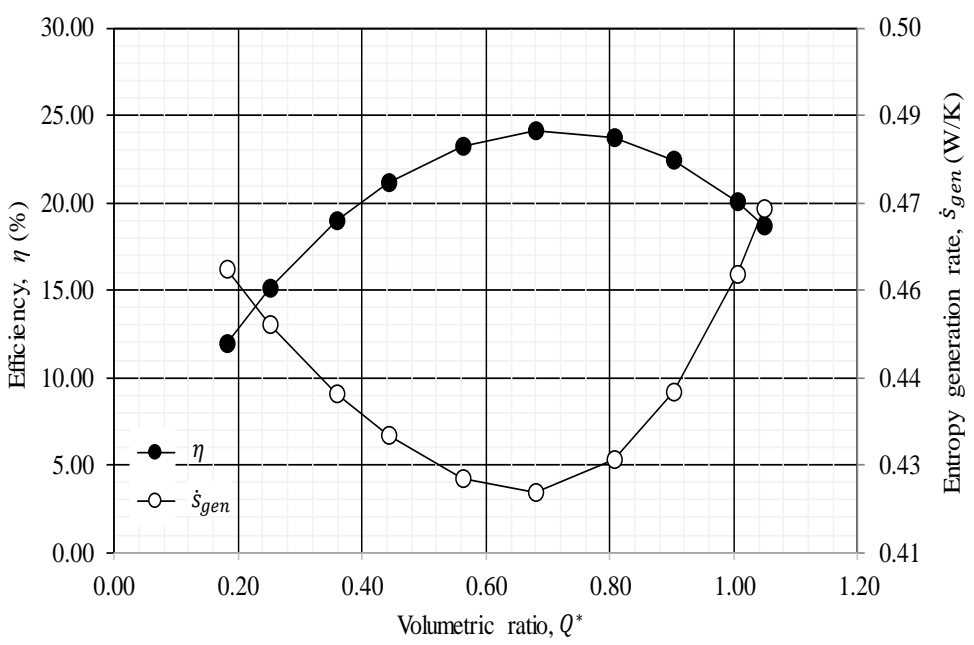

Figure 4. The predicted water jet pump efficiency and entropy generation rate versus the volumetric ratio

\section{Entropy Generation Analysis}

Figure 5 shows contours of the predicted entropy generation, and that of velocity streamlines on each part of the water jet pump at the best efficiency point $\left(\eta_{\max }\right)$. We can see that the entropy generation near the wall is high because velocities change rapidly near the wall, especially at the inlet zone (Figure 5(a)) and the nozzle zone (Figure 5(b)). The water jet velocity was also increased along the path. At the convergent (Figure 5(c)), the jet velocity was released and created a recirculation at the tip of the nozzle due to colliding with the lower velocity stream. As a result of this effect, the predicted entropy generation has increased. At the chamber section (Figure 5d), the jet velocity induces secondary fluid and forms the velocity field. There are two vortices, which generates due to blocking by secondary fluid stream. The smaller ones at the corner of the chamber were created due to large recirculation. However, the local entropy generation shows a lowlevel contour since the recirculation occurs at the lower velocity of the jet stream. 
(d)

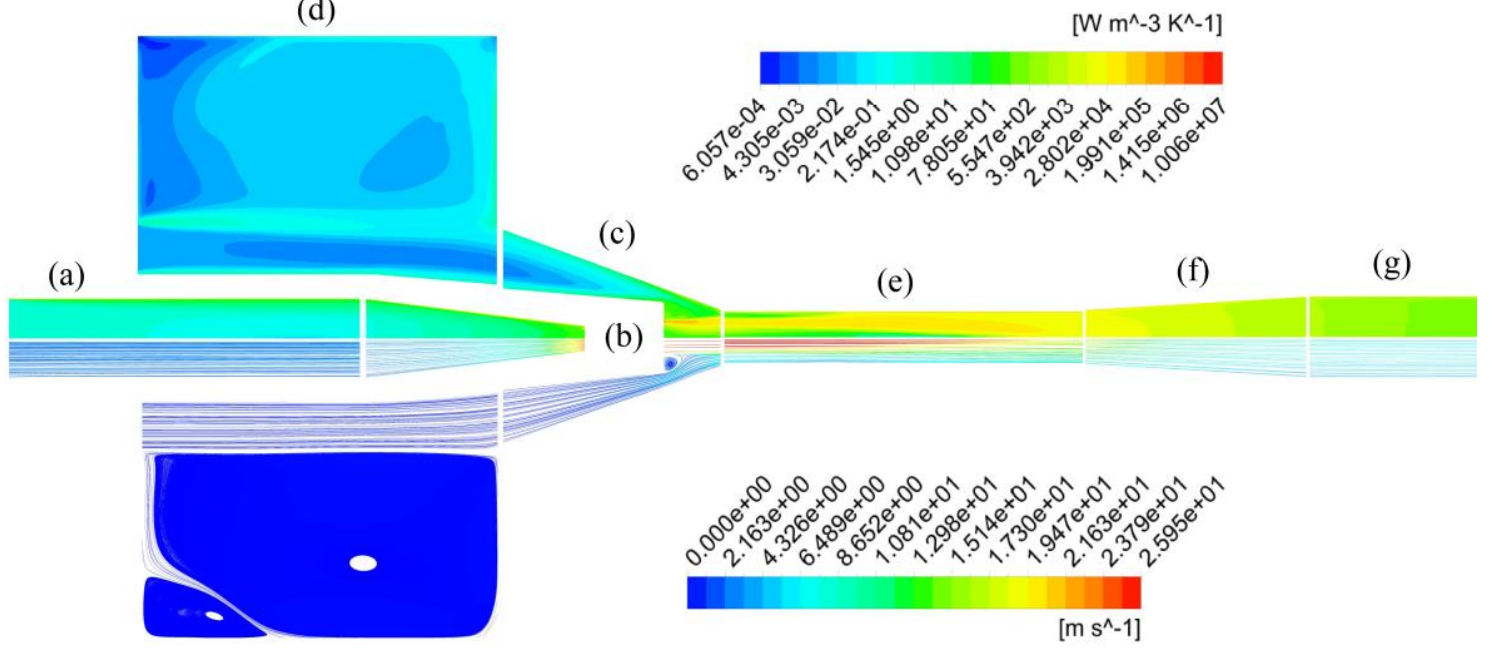

Figure 5. Contours of the predicted entropy generation and that of velocity streamline on each part of the water jet pump at the best efficiency point $\left(\eta_{\max }\right)$ : (a) inlet zone, (b) nozzle, (c) convergent, (d) chamber, (e) throat, (f) diffuser and $(\mathrm{g})$ outlet zone

Further, the predictions show that the entropy generation has increased as the result of the appearance of the shear stress layer between two different velocity streams at the convergent. This velocity field flows along the throat (Figure 5(e)) and the diffuser (Figure 5(f)), where both streams form the uniform mixture. The entropy generation has increased considerably in the throat section. After that, the entropy generation gradually decreases in the diffuser (Figure 5(f)), and outlet zone (Figure $5(\mathrm{~g})$ ). Figure $5(\mathrm{~g})$ depicts that there is no recirculation appears in the outlet zone. The entropy generation in the outlet zone is higher than in the chamber due to the deceleration of the mixing flow.

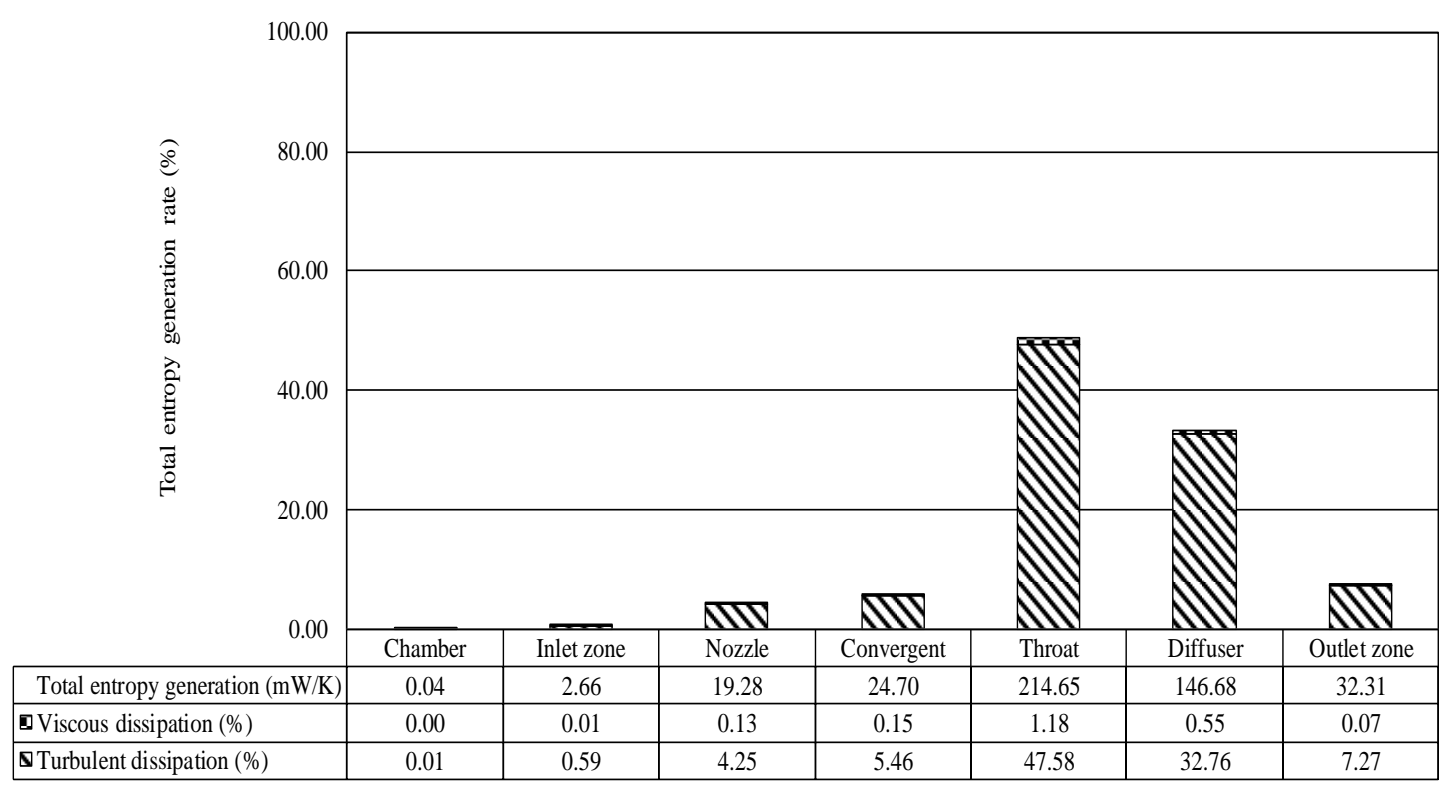

Figure 6. Percentage of entropy generation rate by vicious and turbulent dissipation in each part of the water jet pump at the best efficiency point $\left(\eta_{\max }\right)$

One interesting feature of Eq. (15) is that the total entropy generation due to dissipation can be split into viscous dissipation and turbulent dissipation. So, it enables one to quantify the contribution of each term on the whole entropy generation on each part of the water jet pump. For clarity, the entire entropy generation is determined in each term and plotted, as shown in Figure 6. The primary source of entropy during the mixing process comes from turbulent dissipation, which dominates more than $70 \%$ of the total entropy generation, which close to our previous results [21]. These distributions of entropy generation indicate that these are low at the inlet of secondary fluid and that of primary fluid. Then gradually increases from the nozzle to the converging section and suddenly increases at the throat section. After that, the entropy generation decreases continuously along with the flow from the diffuser to the outlet zone. 


\section{Effect of Projection Ratio at Constant Throat-Aspect Ratio}

The value of the projection ratio determined the location of the nozzle, which was directly influenced by the suction area of secondary flow. As a consequence, the suction area was narrower or smaller when the projection ratio $\left(L_{x}^{*}\right)$ is low. Inversely, the higher value of the projection ratio, the higher the suction area, as shown in Figure 7 . In this study, the effect of the projection ratio on the entropy generation rate at a throat-aspect ratio $\left(L_{t}^{*}\right)$ equal to 5 was investigated based on the optimum operating condition of the experiment.

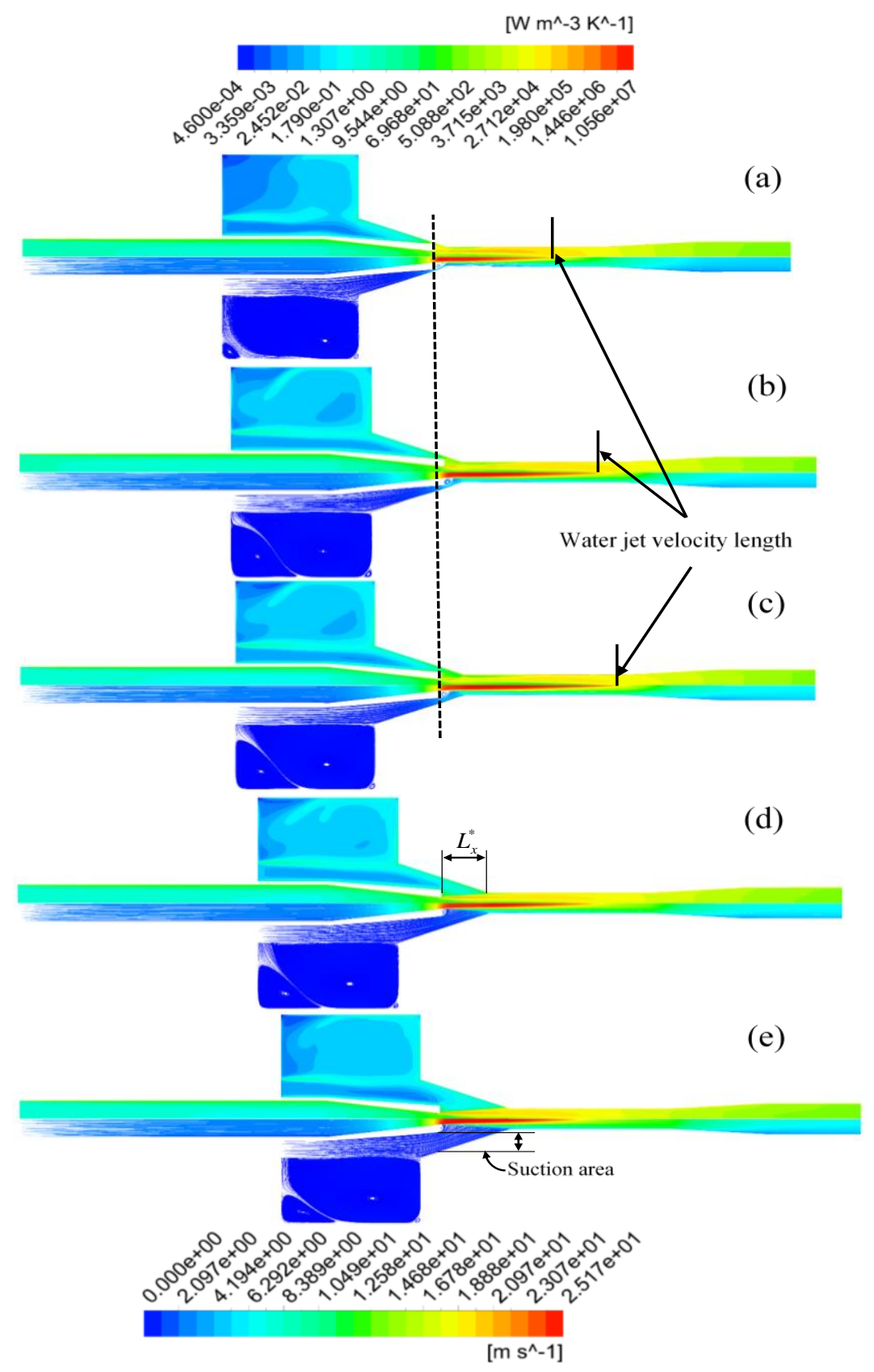

Figure 7. The contour of local entropy generation (top side) and velocity streamline (bottom side) at different projection ratio: (a) $L_{x}^{*}=0.5$, (b) $L_{x}^{*}=0.75$, (c) $L_{x}^{*}=1$, (d) $L_{x}^{*}=2$, and (e) $L_{x}^{*}=3$

By increasing the projection ratio, the suction area of entrained flow becomes larger. Nevertheless, the loss of momentum due to the enormous velocity different affected the amount of entrained flow. Based on Newton's second law, the rate of the momentum of turbulent flow is equivalent to shear stress across the plane. The two streams with different velocity collide with each other, and the faster fluid stream exerts an accelerating force on the slower fluid stream. According to Figure 7(a), streamline water jet velocity moves along the throat and dissipated at the throat exit, while the shear stress layer of the two streams grows from the nozzle tip to the middle of the throat. The apparent turbulent shear stress layer corresponds with the appearance of the highest entropy generation location as seen in the local entropy generation contour. 
Regarding Figure 7(b) to 7(e), increasing the projection ratio is responsible for the growth of the shear stress layer as well as local entropy generation. Besides, the water jet velocity length is influenced by the projection ratio. The most extended jet length is identified in Figure 7(c), among others.

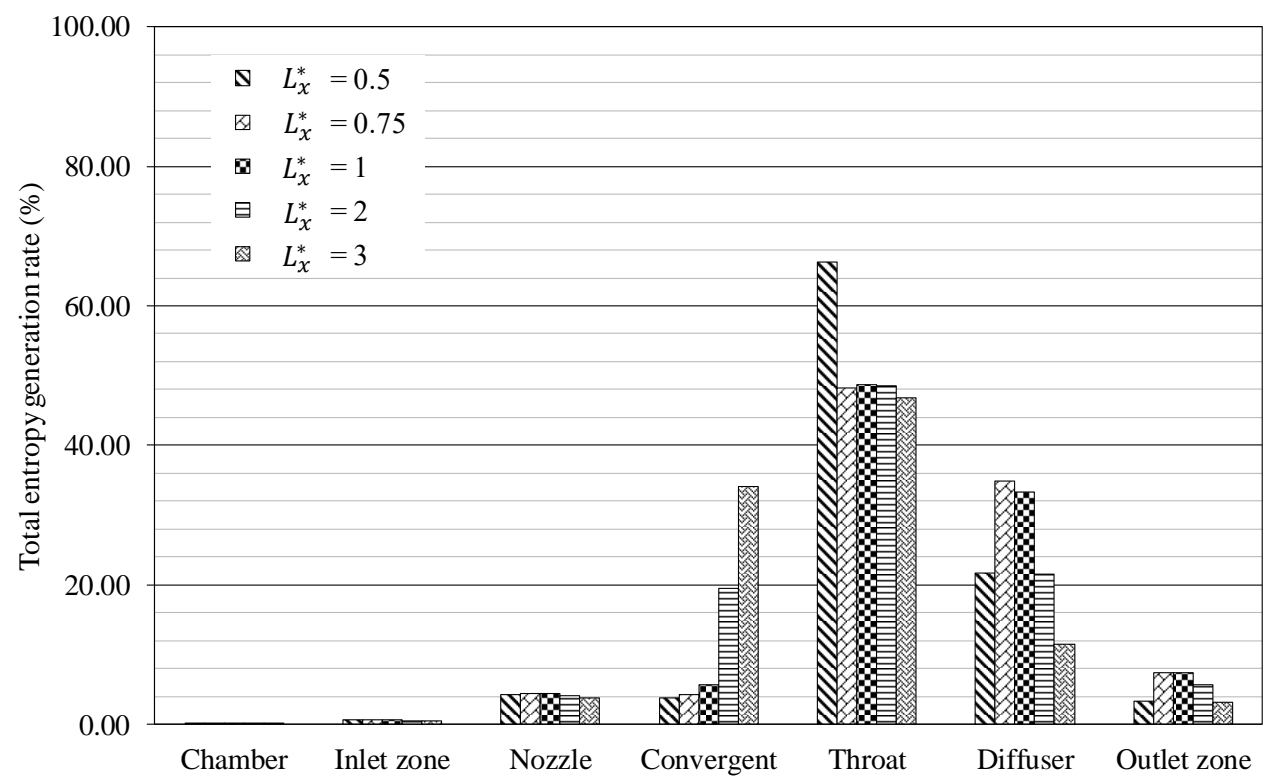

Figure 8. Percentage of total entropy generation in each part of the water jet pump at the best efficiency point $\left(\eta_{\max }\right)$ at different projection ratio

Figure 8 shows the effect of various projection ratios on the distribution of entropy generation. Varies projection ratio mostly influences the distribution of entropy generation in the convergent, throat, and diffuser. One interesting point, the entropy generation significantly increases in the throat at $L_{x}^{*}=0.5$.

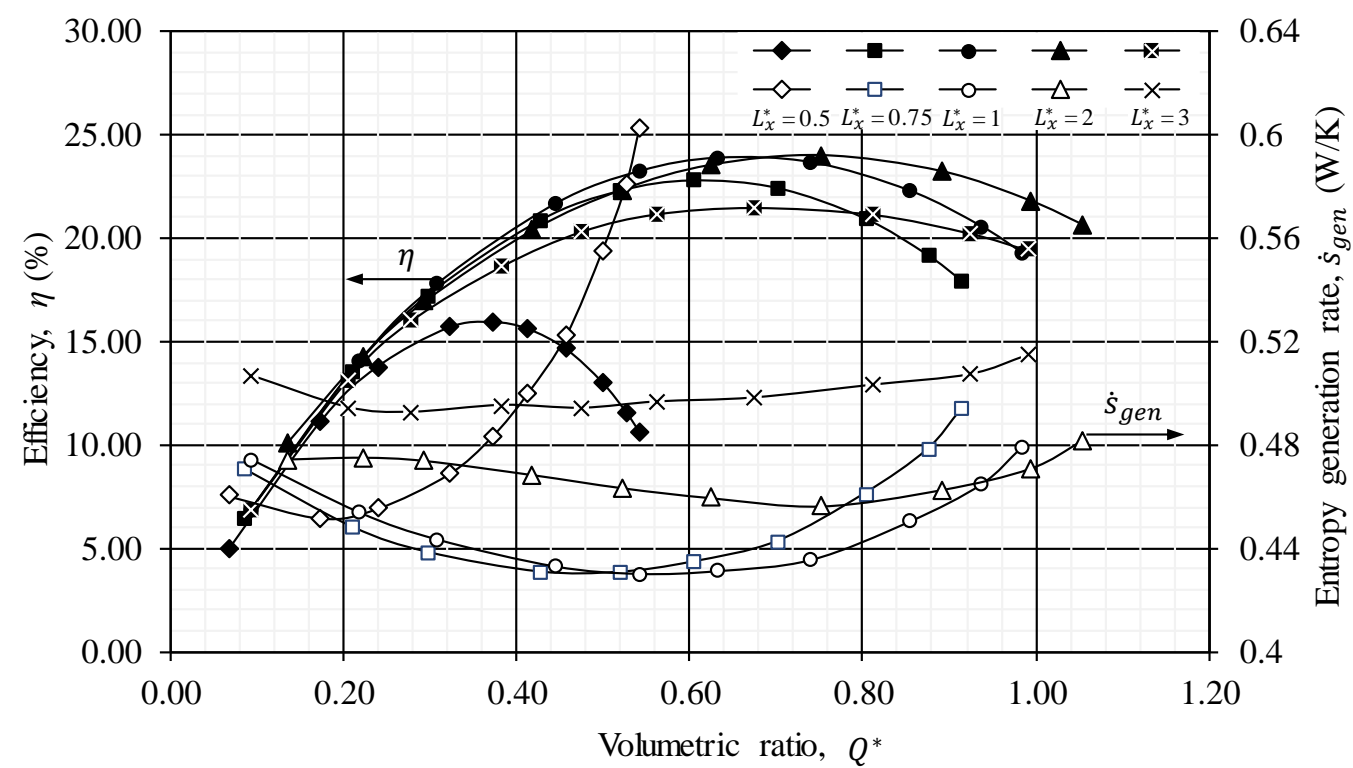

Figure 9. Performance and total entropy generation rate at different projection ratio

Figure 9 shows the effect of various projection ratios on the entropy generation rate as well as efficiency. From the five varies of projection ratio, the optimum efficiency and minimum entropy generation rate are stable from $L_{x}^{*} 0.75$ to $L_{x}^{*}=1$. For instance, efficiency is degraded sharply as the effect of decreasing $Q^{*}$ in each point at $L_{x}^{*}=0.5$. It is also followed by increasing entropy generation rate gradually. A similar pattern also happens at $L_{x}^{*}=3$. Although the performance $\left(Q^{*}\right.$ and $\left.\eta\right)$ in each data point is slightly better than $L_{x}^{*}=0.5$. The lower $\eta$ and higher $\dot{S}_{g e n}$ are persisted comparing to the others. By considering the highest $\eta$ and minimum $\dot{s}_{g e n}, L_{x}^{*}=1$ satisfies the criteria. 


\section{Effect of Throat-Aspect ratio at Constant Projection Ratio}

The appropriate throat-aspect ratio was purposed to obtain an optimum mixing process and optimum momentum transfer of both streams. This section discussed the effect of various throat ratios on the entropy generation rate at a projection ratio equal to 1 .

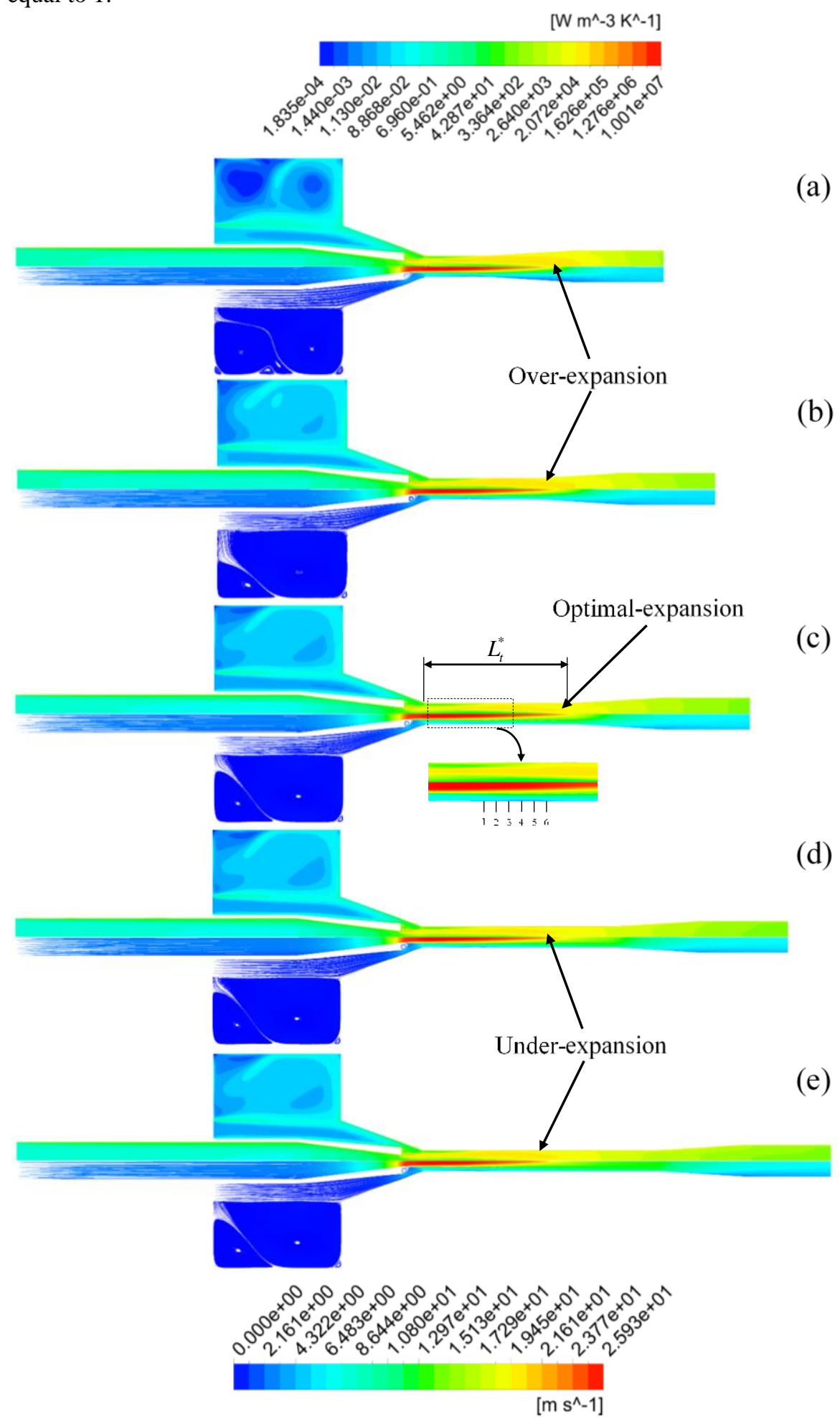

Figure 10. Contour of local entropy generation (top side) and velocity streamline (bottom side) at different throataspect ratio: (a) $L_{t}^{*}=3$, (b) $L_{t}^{*}=5$, (c) $L_{t}^{*}=7$, (d) $L_{t}^{*}=9$ and (e) $L_{t}^{*}=11$

Figure 10 shows the local entropy generation and velocity streamline of each throat-aspect ratio. To understand the local entropy generation behaviour, it is analogous to the velocity streamline. It helps to understand the momentum transfer in the throat by identifying water jet length and deceleration. There are three conditions related to the location of water jet deceleration, i.e., over, optimal, and under-expansions. Figure 10(a) and 10(b) depict both velocities streamline, and local entropy generation distributes along the throat section to the diffuser. In this condition, the local entropy 
generation rate and water jet velocity decelerate out of the throat section, which is known as over-expansion. Since the water jet length decelerates in the diffuser, the momentum action is not fully transferred to the secondary flow due to the inadequate throat-aspect ratio. Figure 10(c) illustrated that both velocity streamline and entropy generation have sufficient throat-aspect ratio. The kinetic energy of the water jet is dissipated at the throat exit, and it also decelerates along to the diffuser. At this point, the local entropy generation is optimal expansion. Later, local entropy generation rate underexpansion condition - the velocity streamline decelerates earlier in the throat section is illustrated in Figure 10(d) and 10(e). As a consequence, the entropy generation with corresponding to energy loss concentrates in the throat section. Furthermore, the separation process in the throat is spotted at a certain throat length. Later, the velocity profile is used to identify the separation process. For instance, six planes are drawn in the throat-aspect ratio equal to 7 is shown in Figure 10(c).

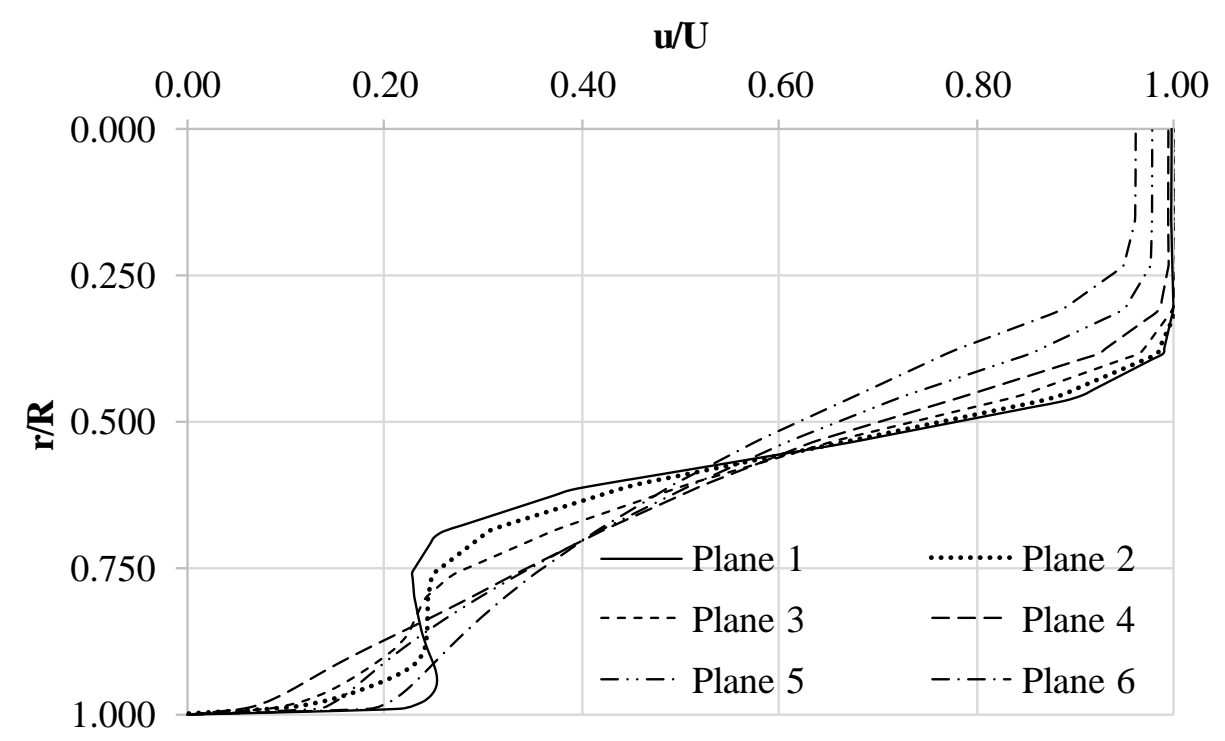

Figure 11. Velocity stream profiles

Figure 11 shows the velocity profile of each plane in terms of the dimensionless variable of the velocity stream with respect to the radius of the throat. The separation flow region is identified at planes 1 and 2, which represented the deflection point of the velocity profile. The separation process takes place between plane 3 and 4 . It can be seen from the zero slopes between velocity profiles to the wall. Then, weak adverse gradients are illustrated in the velocity profile at planes 5 and 6, which means no separation.

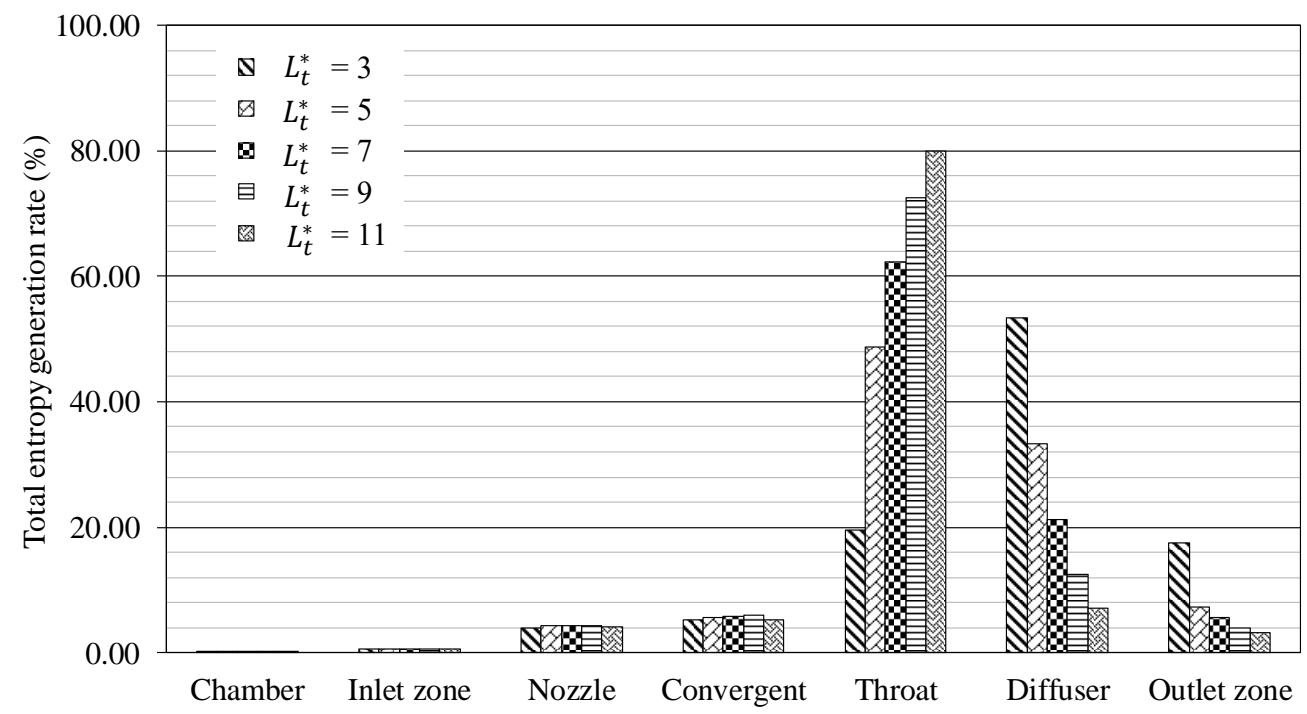

Figure 12. Percentage of total entropy generation in each part of the water jet pump at the best efficiency point $\left(\eta_{\max }\right)$ at different throat-aspect ratio

Figure 12 depicts the influence of various throat-aspect ratios in total entropy generation distribution. The distribution concentrates on the throat, diffuser, and outlet zone parts. The distribution of entropy generation concentrates on the throat, diffuser, and outlet zone parts. Increasing $L_{t}^{*}$ from 3 to 11 raises the entropy generation percentage in the throat. As a result, the entropy generation declines in the diffuser and outlet zone. 


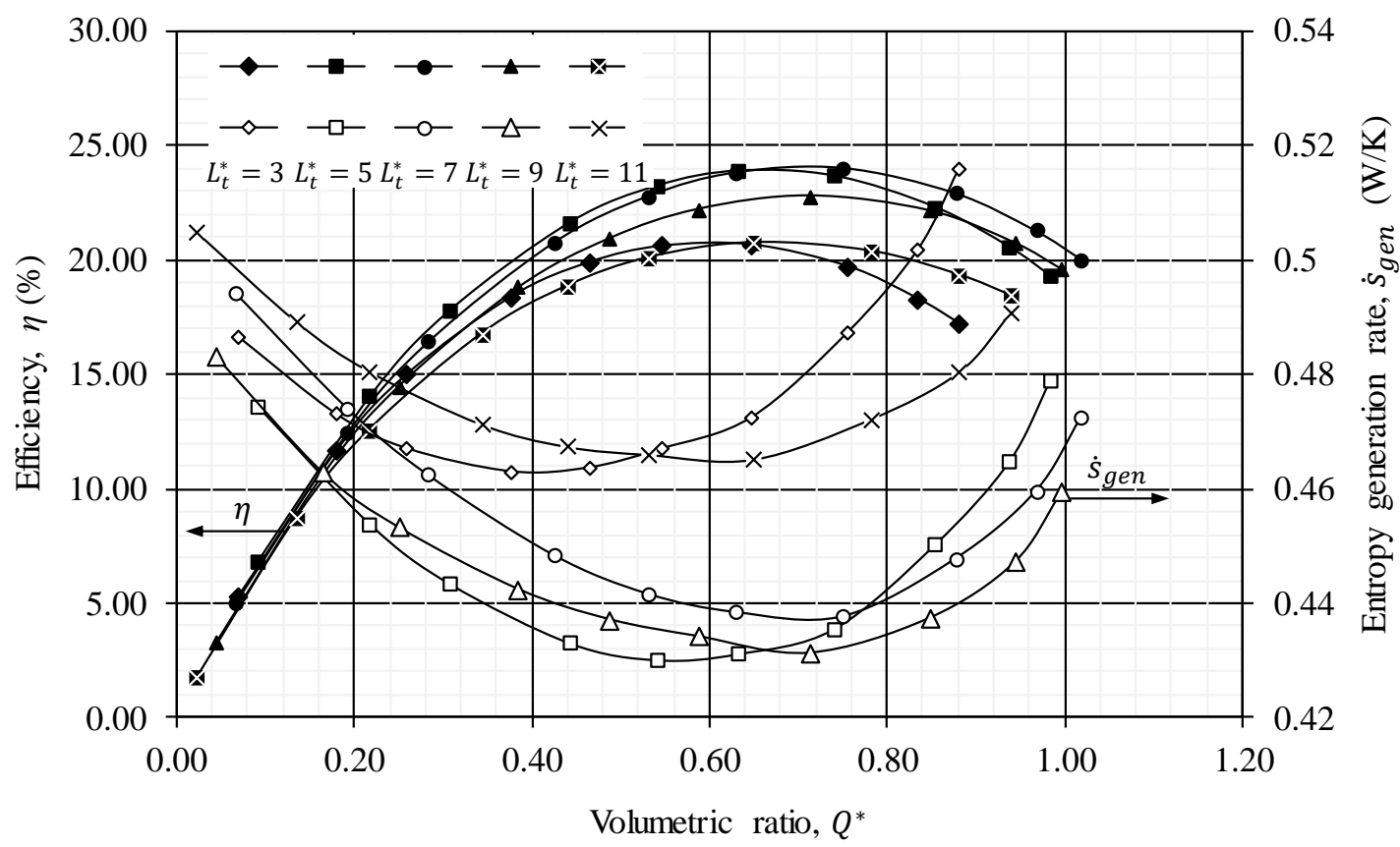

Figure 13. Performance and entropy generation rate at the different throat-aspect ratio

Figure 13 shows the relation between performance and entropy generation affecting the throat-aspect ratio. The entropy generation rate different among of them is not much different, which the minimum entropy generation was identified at $L_{t}^{*}=5$ and $L_{t}^{*}=9$. The optimum efficiency between $L_{t}^{*}=5$ and $L_{t}^{*}=7$ is quite similar, while the other is a little bit lower. However, $L_{t}^{*}=5$ also offers an extensive range of volumetric ratios among the others. This result helps to judge appropriate configuration from the energy utilisation aspect.

\section{CONCLUSIONS}

Numerical studies on a water jet pump were used to determine the optimum performance of the water jet pump. As a passive ejector, two geometry parameters (projection ratio and throat-aspect ratio) were selected for investigating the effects on the performance from the viewpoint of entropy generation. The results of the experiment and CFD modelling was in good agreement as well as the entropy generation. The entropy generation, due to turbulent dissipation, dominated the total entropy generation rate in each operating point. The source was mostly caused by a turbulent shear stress layer between two streams collision.

The projection ratio affected the entropy distribution in the converging and throat section. Increasing the projection ratio decreased the volumetric as well as increasing entropy generation. Furthermore, the throat-aspect ratio affects the entropy distribution in the throat and the diffuser sections. The insufficient throat-aspect ratio decreased the performance in terms of pressure ratio, and it also concentrated on the entropy generation rate in the diffuser. In contrast, excessive throat-aspect ratio reduced the volumetric ratio by concentrating the entropy generation rate in the throat. In essence, the optimum performance of the jet pump obtained in this study was identified at $L_{t}^{*}=1$ and $L_{x}^{*}=5$, respectively. However, further studies effect of other geometry parameters on the turbulent shear stress layer and cavitation phenomena based on entropy generation perspective are required to be investigated and analysed.

\section{ACKNOWLEDGMENTS}

The authors would like to express their gratitude to the Faculty of Engineering, The Petchra Pra Jom Klao PhD scholarship, Grant No. 1/2559, the King Mongkut's University of Technology Thonburi and Center for Energy Technology and Environment (CEE), PERDO, Ministry of Higher Education, Science, Research and Innovation for the financial support provided to perform this study.

\section{REFERENCES}

[1] C. Prabkeao and K. Aoki, "Study on the optimum mixing throat length for drive nozzle position of the central jet pump," $J$. Vis., vol. 8, no. 4, pp. 347-355, 2005, doi: 10.1007/BF03181554.

[2] I. E. L. Neto, "Maximum suction lift of water jet pumps," J. Mech. Sci. Technol., vol. 25, no. 2, pp. 391-394, 2011, doi: $10.1007 / \mathrm{s} 12206-010-1221-7$. 
[3] K. Aldaş and R. Yapıcı, "Investigation of effects of scale and surface roughness on efficiency of water jet pumps using CFD," Eng. Appl. Comput. Fluid Mech., vol. 8, no. 1, pp. 14-25, Jan. 2014, doi: 10.1080/19942060.2014.11015494.

[4] G. Yuan, L. Zhang, H. Zhang, and Z. Wang, "Numerical and experimental investigation of performance of the liquid-gas and liquid jet pumps in desalination systems," Desalination, vol. 276, no. 1, pp. 89-95, 2011, doi: 10.1016/j.desal.2011.03.029.

[5] R. L. Yadav and A. W. Patwardhan, "Design aspects of ejectors: effects of suction chamber geometry," Chem. Eng. Sci., vol. 63, no. 15, pp. 3886-3897, 2008, doi: 10.1016/j.ces.2008.04.012.

[6] J. R. Cairns and T. Y. Na, “Optimum design of water jet pumps,” J. Eng. Power, vol. 91, no. 1, pp. 62-68, Jan. 1969, doi: 10.1115/1.3574677.

[7] R. G. Cunningham, "Gas compression with the liquid jet pump,” J. Fluids Eng., vol. 96, no. 3, pp. 203-215, 1974, doi: 10.1115/1.3447143.

[8] H. J. Henzler, “Zur auslegung von strahlsaugern für einphasige stoffsysteme,” Chemie Ing. Tech., vol. 54, no. 1, pp. 8-16, Jan. 1982, doi: 10.1002/cite.330540103.

[9] M. Nasr, M. A. Hosien, E. M. Wahba, and A. A. A. Sheha, "Computational and experimental study on the water-jet pump performance under different geometrical and operational parameters," ERJ. Eng. Res. J., vol. 40, no. 2, pp. 107-117, 2017, doi: 10.21608/erjm.2017.66340.

[10] T. Meakhail and I. Teaima, "Experimental and numerical studies of the effect of area ratio and driving pressure on the performance of water and slurry jet pumps," Proc. Inst. Mech. Eng. Part C J. Mech. Eng. Sci., vol. 226, no. 9, pp. 2250-2266, Nov. 2011, doi: 10.1177/0954406211430458.

[11] A. A. Saker and H. Z. Hassan, "Study of the different factors that influence jet pump performance," Open J. Fluid Dyn., vol. 3, no. 2, pp. 44-49, 2013, doi: 10.4236/ojfd.2013.32006.

[12] M. P. Helios and W. Asvapoositkul, "Numerical investigation of projection ratio effects on performance of liquid-gas ejector," in 9th TSME-ICOME, International Conference on Mechanical Engineering, 2018, pp. 420-427.

[13] R. Yapıcı and K. Aldaş, "Optimization of water jet pumps using numerical simulation,” Proc. Inst. Mech. Eng. Part A J. Power Energy, vol. 227, no. 4, pp. 438-449, Jun. 2013, doi: 10.1177/0957650913487529.

[14] J. Fan et al., "Computational fluid dynamic analysis and design optimization of jet pumps," Comput. Fluids, vol. 46, no. 1, pp. 212-217, 2011, doi: 10.1016/j.compfluid.2010.10.024.

[15] R. Gong, H. Wang, L. Chen, D. Li, H. Zhang, and X. Wei, "Application of entropy production theory to hydro-turbine hydraulic analysis," Sci. China Technol. Sci., vol. 56, no. 7, pp. 1636-1643, 2013, doi: 10.1007/s11431-013-5229-y.

[16] H. Hou, Y. Zhang, Z. Li, T. Jiang, J. Zhang, and C. Xu, "Numerical analysis of entropy production on a LNG cryogenic submerged pump," J. Nat. Gas Sci. Eng., vol. 36, pp. 87-96, 2016, doi: https://doi.org/10.1016/j.jngse.2016.10.017.

[17] D. Li, H. Wang, Y. Qin, L. Han, X. Wei, and D. Qin, "Entropy production analysis of hysteresis characteristic of a pumpturbine model," Energy Convers. Manag., vol. 149, pp. 175-191, 2017, doi: 10.1016/j.enconman.2017.07.024.

[18] X. Li, Z. Jiang, Z. Zhu, Q. Si, and Y. Li, "Entropy generation analysis for the cavitating head-drop characteristic of a centrifugal pump," Proc. Inst. Mech. Eng. Part C J. Mech. Eng. Sci., vol. 232, no. 24, pp. 4637-4646, Jan. 2018, doi: $10.1177 / 0954406217753458$.

[19] F. Kock and H. Herwig, "Entropy production calculation for turbulent shear flows and their implementation in CFD codes," Int. J. Heat Fluid Flow, vol. 26, no. 4, pp. 672-680, 2005, doi: 10.1016/j.ijheatfluidflow.2005.03.005.

[20] J. Sierra-Pallares, J. García del Valle, P. García Carrascal, and F. Castro Ruiz, "A computational study about the types of entropy generation in three different R134a ejector mixing chambers," Int. J. Refrig., vol. 63, pp. 199-213, 2016, doi: 10.1016/j.ijrefrig.2015.11.007.

[21] M. P. Helios and W. Asvapoositkul, "Entropy generation analysis of water jet pump using computational fluid dynamics," in 9th TSME-ICOME, International Conference on Mechanical Engineering, 2018, pp. 413-420.

[22] H. Yapici, N. Kayatas, N. Kahraman, and G. Bastürk, "Numerical study on local entropy generation in compressible flow through a suddenly expanding pipe," Entropy, vol. 7, no. 1. 2005, doi: 10.3390/e7010038.

[23] X. P. Long, Q. L. Zeng, X. L. Yang, and L. Xiao, "Structure optimization of an annular jet pump using design of experiment method and CFD," IOP Conf. Ser. Earth Environ. Sci., vol. 15, no. 5, p. 52020, 2012, doi: 10.1088/1755-1315/15/5/052020.

[24] Q. Lyu, Z. Xiao, Q. Zeng, L. Xiao, and X. Long, "Implementation of design of experiment for structural optimization of annular jet pumps," J. Mech. Sci. Technol., vol. 30, no. 2, pp. 585-592, 2016, doi: 10.1007/s12206-016-0112-y.

[25] H. Herwig and F. Kock, "Direct and indirect methods of calculating entropy generation rates in turbulent convective heat transfer problems," Heat Mass Transf., vol. 43, no. 3, pp. 207-215, 2007, doi: 10.1007/s00231-006-0086-x.

[26] B. E. Launder and D. B. Spalding, "The numerical computation of turbulent flows," Comput. Methods Appl. Mech. Eng., vol. 3, no. 2, pp. 269-289, 1974, doi: 10.1016/0045-7825(74)90029-2.

[27] M. P. Helios, "Experimental study performance and entropy generation analysis of ejector," Ph.D. dissertation, The Joint Graduate School of Energy and Environment, King Mongkut's University of Technology Thonburi, Bangkok,Thailand, 2020. 